Arab World English Journal (AWEJ) Special Issue on Covid 19 Challenges April 2021

DOI: https://dx.doi.org/10.24093/awej/covid.1

Pp. 3-20

\title{
English K-12 Teacher Experiences in Saudi Arabia in the Pandemic Era: A Follow-up Study of One Khbrat University Program
}

\author{
Ahlam Daraghmeh \\ English Language Institute \\ University of Delaware, USA \\ Corresponding Author: ahlam.musa@ outlook.com
}

\author{
Hilary Mead \\ College of Education and Human Development \\ University of Delaware, USA
}

Kathleen Copeland

English Language Institute

University of Delaware, USA

Received: 3/5/2021

Accepted: 4/7/2021

Published: 4/26/2021

\section{Abstract}

A mixed-methods study examines the impact of the pandemic-driven move to virtual learning on K-12 (kindergarten through twelfth grade) English teacher experiences in Saudi Arabia to inform future development of the teaching of English in the country. Research is limited in K-12 English instruction in the country, and it is just emerging on the pandemic's impact on education in the MENA region. The 35 subjects were English educators who completed the Saudi government-sponsored professional development program, Khbrat, at one U.S. university. Contextualized within the literature on technology in instruction, leadership frameworks, and Vision 2030 education reforms, the study explores the convergence of technological, institutional, and socio-cultural factors affecting innovation in English education to address the research question of how the pandemic has impacted Khbrat graduates as EFL teachers and as change agents in their country. Integrated analysis of survey and interview data reveals patterns of both acceleration and constraint. Findings suggest pathways to leverage virtual technology and acquired knowledge and skills of Khbrat English teacher graduates to deliver EFL professional development with a more pedagogical focus and to build coalitions among EFL educators to sustain the forward movement of innovation in English education in post-pandemic Saudi Arabia. The study concludes with recommendations for future applications.

Keywords: Covid-19 pandemic, English as a Foreign Language, professional development, Saudi Arabia, virtual education

Cite as: Daraghmeh, A., Mead, H. , \& Copeland, K. (2021). English K-12 Teacher Experiences in Saudi Arabia in the Pandemic Era: A Follow-up Study of One Khbrat University Program. Arab World English Journal (AWEJ) Special Issue on Covid 19 Challenges (1) 3-20.

DOI: https://dx.doi.org/10.24093/awej/covid.1 
Arab World English Journal (AWEJ) Special Issue on Covid 19 Challenges April 2021

English K-12 Teacher Experiences is Saudi Arabia in the Pandemic Era

Daraghmeh, Mead

\section{Introduction}

The global disruption of the coronavirus pandemic led many countries to close schools, affecting millions of students (UNESCO, 2020). In March 2020, Saudi Arabia started the shift from in-person to distance learning. Within one week of the country's first confirmed coronavirus case, the Kingdom of Saudi Arabia Ministry of Education (MoE) moved K-12 schools to an online environment, with nationwide distance learning beginning the day after schools closed (Ministry of Education, 2020). Due to this emergency-characterized change, it is essential to record the recent experiences of teachers during these unstable times and explore possible outcomes that may influence the future of the teaching and learning experiences of all involved.

In the U.S., similar conditions and emergency responses occurred. Within this global context, a Saudi government-sponsored educational leadership initiative was underway at the U.S. university where researchers conduct this study. The Khbrat program was an initiative launched by the MoE between 2017 and 2020, partnering with universities worldwide to equip Saudi K-12 educators through a year-long professional learning program to become change agents in the transformation of Saudi schools, in service of the Kingdom's Vision 2030 (Ministry of Education, 2018). Khbrat scholars produced a research-based project focusing on innovation for Saudi schools. The host university for this study provided one year of intensive Professional Development (PD) and cross-cultural experience in K-12 schools to two cohorts totaling 90 teachers between 2018 and 2020 (hereafter identified as Cohort Two and Cohort Three). Teachers of English and other disciplines collaborated with university mentors to build capacity as educational leaders and develop action plans for implementation when they returned home.

A previous study, conducted shortly before the pandemic, inquired into the impact of the program on Cohort Two (2018-2019), yielding insights into shifts in self-perception as leaders and highlighting the importance of systematic post-program support and the value of qualitative inquiry into program impacts (Bentahar, Copeland, \& Stevens, 2020).

The current study builds on the first. First, it focuses on the experiences of English as a Foreign Language (EFL) teachers and examines pedagogical development in this field. Second, it explores how the pandemic-driven move to a virtual learning environment impacted participants as educators and change agents in Saudi education. Third, while retaining a mixedmethod design, it uses qualitative data more extensively to explore teacher experiences. The study addresses the following question: How did the pandemic impact EFL teachers from this university Khbrat program as change agents in their country? Thus, researchers aim to explore the current experiences of these teachers during the pandemic in order to identify areas of possible development that may inform the forward movement of the teaching of English as a foreign language in Saudi Arabia.

A difference between the experiences of Cohorts Two and Three should be noted. Cohort Two teachers experienced all phases of the pandemic response detailed above while working as teachers or supervisors in Saudi schools. However, Cohort Three was nearing the completion of their year in the U.S. when the pandemic disrupted education worldwide, forcing mass migration to an online environment. The Khbrat program at this university also migrated online. After graduation in May 2020, Cohort Three returned to very different educational challenges in Saudi Arabia than they left the year before. 
Arab World English Journal (AWEJ) Special Issue on Covid 19 Challenges April 2021

English K-12 Teacher Experiences is Saudi Arabia in the Pandemic Era

Daraghmeh, Mead

\section{Literature Review}

Saudi Arabia has invested heavily in both K-12 and higher education as part of Vision 2030, in part through digital learning initiatives and in the development of EFL education, as English plays a vital role in the economic, political, and cultural sectors of the country (AlZahrani \& Rajab, 2017; Faroque, 2017). English is the only foreign language taught at public universities in Saudi Arabia, hence, its position in K-12 education (Alharbi, 2019). Overall, there are high expectations about the role of English in the country's Vision 2030 (Al-Shehri, 2020).

The swift national transition by Saudi Arabia to virtual learning in response to the pandemic, praised by UNESCO (Oxford Business Group, 2020), necessitated the adoption of "robust" and "dynamic" technology to ensure the continuation of the educational process at all levels (Ministry of Education, 2020). Initially, K-12 students had multiple options for accessing curriculum asynchronously through existing technology such as the Noor platform and iEN National Educational Portal/iEN YouTube channel or satellite TV (Ministry of Education, 2020). These offered videos, downloadable textbooks, and other resources covering the curriculum (Bozkurt et al., 2020).

In the first semester of 2020-21, schools remained online with several changes. First, the MoE launched the Madrasati platform (Arabic for "My School"), which was linked to Microsoft 365 applications and provided a coordinated system for accessing/delivering content, submitting assignments, and communicating. All students, parents, and educators were expected to join the platform, and online synchronous classes were held using Microsoft Teams (Saudi Gazette, 2020). Attendance and academic accountability resumed and could be monitored through the Madrasati dashboard. The iEN channels remained an option for students without reliable internet access. El-Saharty, Kheyfets, Herbst, and Ajwad (2020) view the pandemic disruption as an opportunity to further accelerate educational reforms set by Vision 2030 through the rapid adoption and ongoing accessibility of new educational technologies.

Concurrently, the MoE adopted a single textbook series for EFL education nationwide. This was part of a planned multi-year strategy in which different regions piloted different materials and compared results. Because of the simultaneous pandemic shift, students and teachers now began using the online versions of the adopted curriculum, affording further integration of technology into instruction (Al-Shehri, 2020).

As trends in EFL pedagogy have evolved over the years, the Communicative Approach, emphasizing language acquisition through authentic and meaningful communication, has gained wide acceptance (Rahman, 2015). According to Mabrook and Mabrook (2020), this approach has been beneficial to English language learners in Saudi universities if balanced to cover all language skills.

Despite many initiatives in Saudi Arabia, student performance in English language learning has remained low (Alrabai, 2016). Factors mentioned in the literature include outdated learning practices such as memorization, misalignment of curriculum to students' needs, limited exposure to the target language, and lack of student motivation (Al-Zahrani \& Rajab, 2017; Faroque, 2017; Hasan, 2012). Mabrook and Mabrook (2020) suggested that Saudi EFL students are less involved in learning because they are not accustomed to the authentic practice of oral 


\section{Arab World English Journal (AWEJ) Special Issue on Covid 19 Challenges April 2021}

English K-12 Teacher Experiences is Saudi Arabia in the Pandemic Era

Daraghmeh, Mead

productive skills. Outdated instructional paradigms persist, which view students as receivers of information, meeting class requirements through mechanical tasks and fixed response assessments, often receiving minimal feedback (Hasan, 2012). More importance is placed on covering the curriculum according to a schedule than on targeting language learning according to student proficiency and needs (Al-Shehri, 2020).

Prior to the pandemic, technology in EFL classrooms in many parts of Saudi Arabia was often limited; many schools lacked language labs and other resources such as recorders and projectors, with the exception that some teachers utilized social media and WhatsApp for learning purposes (Alharbi, 2015; Al-Shehri, 2020). Since the pandemic, student-teacher and teacher-teacher communication have been facilitated primarily through technology, revealing the potential to enhance teaching and learning through its affordances of connection, co-creation, flexibility, and convenience (Onyema et al., 2020). Moreover, online education has the capacity to reach more learners (Duhoe, Owusu-Afriyie, \& Kumi, 2020). In Hakim's (2020) research, most teachers asserted that teaching online also affords new ways to deliver English language instruction. Technology can provide tools that benefit both learner and teacher experiences through resources for developing speaking and writing skills (Al-Shehri, 2020; Hakim, 2020), connecting with students through chat platforms, and addressing varying learning styles (AbuRmaileh, 2015). However, Vlachopoulos (2020) warns that new technological learning solutions must be approached systematically in investment, planning, and delivery to ensure effectiveness.

In this new learning environment, differentiation and customization to meet English learner needs may be possible (Tao, Yeh, \& Sun, 2006). Furthermore, Duhoe et al. (2020) found that online learning "facilitates communication and also strengthens the relationships which support learning," (p. 63) but also that this optimistic outlook comes with the requirement of a more intentional investment of effort and time to ensure the optimization of the learning experience.

The SAMR model offers a way to critically examine how technology changes learning experiences as it moves from low-tech to high-tech environments (Puentedura, 2013). According to Puentedura (2013), changes could be mapped onto a continuum "from enhancement to transformation," starting with simple substitution "with no functional change," to augmentation involving "some functional improvement," to modification, allowing for "significant task redesign," to redefinition, which "allows for the creation of new tasks, previously inconceivable," thus effecting a transformation of the learning experience (slide 3 ).

Studies also reveal additional obstacles for English learning in the online environment, mainly relating to student engagement and motivation. Atmojo and Nugroho (2020) assert that different learning styles and language proficiencies create new challenges online, especially with low proficiency learners. Furthermore, learners must have an increased awareness of online learning norms and develop a more autonomous mindset. Atmojo and Nugroho found that students often do not fully understand these considerations, perceiving online learning as informal and less important, resulting in less focus and participation. Moreover, in Saudi Arabia where private and public spaces are distinct and family "privacy from the outside is essential" (Nydell, 2018, p.49), webcams are more likely off during virtual instruction, creating an additional potential barrier to the engagement necessary for language learning. 


\section{Arab World English Journal (AWEJ) Special Issue on Covid 19 Challenges April 2021}

English K-12 Teacher Experiences is Saudi Arabia in the Pandemic Era

Daraghmeh, Mead

Assessment is yet another dilemma in online education although in some settings, technology has provided opportunities for creative project-based learning online. Because digital multiple-choice tests are prevalent due to their ease and automaticity, testing higher-order skills has become even more challenging (Atmojo \& Nugroho, 2020). Another issue emerges in accurately measuring outcomes and validating results. In Saudi Arabia, according to Alrabai (2016), "[s]tudents are not usually tested or promoted based on their actual competence in the foreign language"(p. 26) but instead based on memorization. Moreover, at the college level, Mabrook and Mabrook (2020) found that EFL learners often use technology to open a second device to search for answers or to paste exam responses, and can now more easily enlist friends or family to help answer questions or perform tasks.

At the 2016 International Conference of English as a Foreign Language Education, Saudi EFL teachers recognized the need for continuing professional development in achieving the Vision 2030 goals of enhancing English instruction (Al-Zahrani \& Rajab, 2017). A mismatch between instructional best practice and teacher preparation has persisted (Rahman, 2015), with many EFL teachers still using traditional audiolingual and grammar-translation methods (AlShehri, 2020). Zohairy (2012) reported that misconceptions also existed about the purpose and value of teacher PD in Saudi Arabia, at least before the pandemic, and that teachers were not always afforded time in their schedules to attend PD sessions or to implement what they learned.

Now, teachers, students, and parents alike have experienced new and sudden unpreparedness in the use of online technologies, resulting in barriers to effective learning worldwide (Al Salman, Alkathiri, \& Bawaneh, 2021). In addition to PD in English instruction, Hakim (2020) recommends that EFL teachers receive extensive PD to further develop their virtual technology skills to positively impact student success. This training should include digital materials development, feedback tools, motivation strategies, and facilitating online interaction (Atmojo \& Nugroho, 2020).

During uncertain times, leadership plays a vital role in embracing innovations to allow learning and teaching to move forward. The nature of school leadership experienced a key transformation in the pandemic. Professional relationships are significantly altered, with fewer opportunities for informal interactions. Harris (2020) argued that a new model of "distributed, collaborative and networked" (para. 4) leadership is evolving to fill needs in this era of uncertainty and ambiguity. Harris and Jones (2020) argued that this model allows for the voices of stakeholders at all levels of an organization and leverages teacher leadership to move schools forward. Nevertheless, despite significant capital investment in educational reforms over the last 20 years, Alsaleh (2019) attributed a limited impact of these initiatives to "a lack or weak change management and leadership during the implementation stage." (p. 175)

One change management framework directly taught to program participants was Kotter (1996), in which successful transformation requires a coalition of supporters working together and occurs through a series of phases over time. Kotter outlined steps to bring about change, including creating a vision, communicating that vision to others and empowering them to act, and planning for incremental successes before moving on to institutionalize a new approach. 


\section{Arab World English Journal (AWEJ) Special Issue on Covid 19 Challenges April 2021}

English K-12 Teacher Experiences is Saudi Arabia in the Pandemic Era

Daraghmeh, Mead

Saudi Arabia, on the other hand, delivers education through the national centralized leadership of the MoE, which decides all matters of curriculum, policy, evaluation, and training within a curriculum-centered rather than a student-centered educational paradigm. According to Algarni and Male (2014), this model tends to limit the flexibility, autonomy, and voice of potential educational leaders, as well as the capacity to create effective learning environments. Within this context, researchers will explore how EFL teachers, who were to return to Saudi Arabia as change agents, have navigated the challenges of the pandemic to implement their visions for EFL instructional innovations.

This inquiry fills three gaps in the literature discussed here. First, in the MENA region, most EFL research is conducted in higher education, not in K-12 settings (Mabrook \& Mabrook, 2020). Second, research to date is limited about the K-12 educational impact of the pandemic in the region; of 89 pandemic-related studies reviewed by Bond (2020), only 3\% came from the MENA region. Third, researchers aim to address methodological limitations, given that only $4 \%$ of the studies in Bond (2020) used mixed methods.

\section{Methods}

This mixed-methods study uses a convergent design for triangulation purposes (Creswell \& Plano Clark, 2017). Quantitative (survey) and qualitative (interview) data collection proceeded separately but in overlapping timeframes, and then the findings were brought into conversation with each other. Integration, therefore, occurred both in analysis and interpretation.

\section{Participants}

The survey was a census; all Khbrat graduates of the researchers' university were invited to participate. This included 48 from Cohort Two (2018-19) and 42 from Cohort Three (201920). These Saudi educators had all applied to, been selected for, and completed the intensive Khbrat program. Otherwise, they varied both demographically (e.g., gender, region, age) and in terms of their professional context (e.g., role, subject, and level taught). There were 67 survey respondents, a 74\% response rate. This included 32 Academic Content Teachers (ACT) and 35 English as a Foreign Language Teachers (EFL). For the rest of this analysis, only the EFL teachers are included. In this subgroup, the survey response rate was $78 \%$.

Sampling for the interviews combined convenience and purposive approaches. Everyone who completed the survey was sent a link to consent and sign up for an interview, and all volunteers were interviewed. Interview participants were recruited to achieve a representative balance between cohorts and genders and to include supervisor perspectives.

Demographics of survey and interview respondents, compared to the EFL subgroup as a whole, are shown in Table 1 below.

Table 1. Participant Demographics

\begin{tabular}{|l|l|l|l|l|l|l|}
\hline \multirow{2}{*}{} & \multicolumn{2}{l|}{ Cohort } & \multicolumn{2}{l|}{ Gender } & \multicolumn{2}{l|}{ Pre-program Role } \\
\cline { 2 - 8 } & $2(2018-19)$ & $3(2019-20)$ & Male & Female & Teacher & Supervisor \\
\hline Survey Responses & 18 & 17 & 20 & 15 & 31 & 4 \\
\hline
\end{tabular}


Arab World English Journal (AWEJ) Special Issue on Covid 19 Challenges April 2021

English K-12 Teacher Experiences is Saudi Arabia in the Pandemic Era

Daraghmeh, Mead

\begin{tabular}{|l|l|l|l|l|l|l|}
\hline$(\mathrm{N}=35)$ & & & & & & \\
\hline Interviews $(\mathrm{N}=14)$ & 8 & 6 & 8 & 6 & 12 & 2 \\
\hline $\begin{array}{l}\text { Program Participants } \\
(\mathrm{N}=45)\end{array}$ & 25 & 20 & 27 & 18 & 40 & 5 \\
\hline
\end{tabular}

\section{Instruments}

The survey instrument included twenty-four closed-ended questions, some with multiple parts, and seven open-ended questions. These fell into six categories: 1) demographics, 2) employment, 3) action plan implementation, 4) teaching experiences, 5) educational leadership, and 6) final thoughts and recommendations. Only respondents who identified as teachers answered section four. To permit comparisons across studies and with the permission of those researchers, where possible, question formats from Bentahar et al. (2020) were replicated, with additional questions about the pandemic added.

The interview protocol was semi-structured and included nine broad questions with follow-up probes and a final opportunity for participants to share any additional thoughts.

For the survey and the interview, participants could choose to receive and respond to questions in English or Arabic. The Arabic instruments were verified with two external professionals. One member of the research team is a native Arabic speaker; she translated all responses into English before the analysis.

\section{Research Procedures}

The survey was administered in Qualtrics. The link was shared via personalized emails and WhatsApp messages in groups that had been established for each cohort. The survey opened on January 15 and closed on January 29, 2021, with two reminders sent over that period.

Interviews were conducted via Zoom in late January through mid-February 2021 and recorded. Transcripts were obtained through Zoom and, where applicable, translated. All three researchers conducted interviews, which ranged from 30 minutes to almost two hours long.

Closed-ended survey questions were analyzed quantitatively using Qualtrics and Excel. Results were disaggregated to look for differences by gender, cohort, and reassignment (i.e., whether a participant had been moved to a new school). Open-ended survey responses were manually coded for themes.

Interview data were analyzed in Dedoose (SocioCultural Research Consultants, 2020) using an inductive approach and open (constant comparative) coding. One researcher did all coding and initial analysis, but the interpretive process was completed collaboratively. As former Khbrat personnel, the researchers drew on their understanding of the program and their relationships with the participants and sought to recognize their own cultural lenses in conducting the inquiry. 
Arab World English Journal (AWEJ) Special Issue on Covid 19 Challenges April 2021

English K-12 Teacher Experiences is Saudi Arabia in the Pandemic Era

Daraghmeh, Mead

\section{Results}

Integration of survey and interview findings reveals three dimensions of participant experiences in the pandemic: as educators in virtual EFL classrooms, as colleagues interacting with peers and supervisors, and as leaders attempting to implement initiatives within a new educational environment.

\section{Experiences in Classrooms}

Almost all survey respondents (97\%) reported working either entirely online or in a mix of online and in person. Some respondents noted the speed and comprehensiveness of the pivot online as a benefit of a centralized system in a time of great stress. Others understood this pandemic-driven move as a massive acceleration of their country's long-term plans as one participant indicated: "The electronic/technological transformation is a fascinating one. We had never imagined it before. Well, there were plans and visions, but they would have required ten years ahead."

Participants who were current teachers were asked to rate how much the pandemic had changed their teaching approaches. The reported responses are in Table 2.

Table 2. Ratings of pandemic-related change in teaching approaches

\begin{tabular}{|l|l|l|l|l|l|l|}
\hline & $\begin{array}{l}\text { Total } \\
\text { EFL }\end{array}$ & $\%$ & $\begin{array}{l}\text { Cohort } \\
\text { Two } \\
n\end{array}$ & $\begin{array}{l}\text { Cohort } \\
\text { Two } \\
\%\end{array}$ & $\begin{array}{l}\text { Cohort } \\
\text { Three } \\
n\end{array}$ & $\begin{array}{l}\text { Cohort } \\
\text { Three } \\
\%\end{array}$ \\
\hline Changed a lot & 20 & 71.4 & 7 & 50.0 & 13 & 92.9 \\
\hline Changed a little & 8 & 28.6 & 7 & 50.0 & 1 & 7.1 \\
\hline Did not change & 0 & 0.0 & 0 & 0.0 & 0 & 0 \\
\hline
\end{tabular}

As Table 2 shows, all members of both cohorts perceived pandemic-related changes in their teaching. Cohort Three were more likely to call it "a lot" of pedagogical change. One respondent expressed, "...because of covid,... it is like a jump to the 21st century."

These perceptions of change revealed divergent views about the affordances or limitations of online EFL classrooms. Some struggled to identify positives, while others found online teaching "easier" and hoped that they could keep it after the pandemic. While these differences cannot fully be explained, key ideas can be distilled from the data. The rest of this section discusses how teachers experienced this "jump to the 21st century" in their instruction, communication, curriculum, and assessment.

Participants identified rapidly improved technology skills as a benefit of the pandemic, a Vision 2030 goal which, according to one, had previously been slow to take hold. Teaching from home in front of their computers, instead of traveling long distances to school and moving room to room throughout the day, some teachers found more time and better online access.

[English] teachers have maybe gotten benefits from online learning because in the past maybe you'll enter the classroom, you have to plug in to prepare the screen. (...) now just 


\section{Arab World English Journal (AWEJ) Special Issue on Covid 19 Challenges April 2021}

English K-12 Teacher Experiences is Saudi Arabia in the Pandemic Era

Daraghmeh, Mead

your computer and you can provide them with the materials and (...) upload that, they can listen, they can watch

The online environment also created new lines of communication. Teachers, students, and families could connect via the platform, emails, or social media. Participants saw this as an advantage, and some reported that their students were initiating contact.

As described above, KSA adopted one textbook series for EFL nationwide, concurrent with the pandemic, thus motivating teachers to tap into the curriculum's existing online capacity. Some respondents praised the curriculum for integrating a more comprehensive range of language skills in the four domains: listening, speaking, reading, and writing. The general comment that "tech is useful in teaching English as a second language" echoed across all data; however, upon further analysis, the impact of technology appears more varied.

The survey asked teachers how much flexibility they had in "what and how they teach" using a before and after format to gauge pandemic effects. Responses show a shift towards greater flexibility. The number of teachers reporting "a lot" of flexibility grew from three (11\%) before the pandemic to twelve (43\%) once the pandemic began. Yet, respondents also reported that the curriculum continued to operate as a traditional governing structure, with adherence to the textbook and a consistent pace still expected despite new circumstances. Although one teacher commented, "I can use what I want for materials," extra videos or websites supplemented rather than replaced the textbook.

Some teachers experienced increased supervisory visits, facilitated by the online environment, as primarily a check for curricular compliance: "Online you are more monitored than in your [physical] classroom. You have to really stick to your textbook."

Some teachers identified the ease of providing authentic English input online:

...Because you have access to different resources...that kids nowadays really enjoy and they love to participate with it and also they get exposed to native speech.

While there were many comments about increased receptive input (e.g., videos, activities), interview responses revealed a wider range of experiences of communicative productive language practice online.

Some teachers found their students engaged online, and they occasionally shared innovative activities to get them talking. One described how technology helped students find their voice in English:

The shy students who couldn't speak face to face, now they are... the most important stars. Through the online, they can speak, they can give jok[es] in English...They have some confidence...

On the other end of the spectrum were comments such as: 


\section{Arab World English Journal (AWEJ) Special Issue on Covid 19 Challenges April 2021}

English K-12 Teacher Experiences is Saudi Arabia in the Pandemic Era

Daraghmeh, Mead

I have to beg some students to interact and speak...this semester I have 31 students in the class, those who interact with me are four or five. The rest don't even respond... at all even if I call on them all class.

Most descriptions of students' communicative output fell somewhere between these extremes, with increased participation reported by the middle of the school year as teachers found more creative ways to elicit it.

I have to prepare many strategies during the class to attract the students' attention, and ...most of them fun or games to encourage...participation.

Before the availability of Teams breakout rooms in late 2020 one interviewee commented, opportunities for small group interactive practice, typical of face-to-face language classrooms, were not available. Furthermore, the cultural importance of privacy influenced the role of webcams, which usually stayed off for both students and teachers. Consequently, more difficulty was reported in building rapport and modeling pronunciation, conditions for communicative language instruction.

It was challenging teaching... without the physical appearance...especially because we cannot force or ask our students to open their cameras (...) That's difficult to maintain a manageable relationship with your students.

It's still hard for my students and for me to reach each other (...) I tried sometimes to talk and mime and try to open my mouth, but nobody sees me.

As with curricular expectations, centralized assessment policies remained during the pandemic. Yet, the manner in which they were administered and how they impacted students was more flexible, with several revisions to the guidelines for assigning student grades. Data showed that participants experienced the MoE's response in this area in different ways. While some viewed the changes as evidence of decision-makers' responsiveness, others found the frequent policy changes to be "random" and disorienting.

English assessments were administered online in multiple-choice format. Respondents recognized some benefits to automated assessment but also raised many challenges:

You have Forms to do any exam and it's much better than papers, grading ...Everything will be done for you. It saves lots of time, lots of effort. But the student can cheat easily.

Teachers described students copying from each other, looking up answers, and having their relatives take their tests. They also noted the absence of assessments measuring student production:

[Assessments] are not reliable and not valid. There is no credibility or consistency. The questions are multiple choice questions and students benefit from the opportunity of using the book or his brother or someone. They don't give an honest true impression. There is inflation in grades. 
Arab World English Journal (AWEJ) Special Issue on Covid 19 Challenges April 2021

English K-12 Teacher Experiences is Saudi Arabia in the Pandemic Era

Daraghmeh, Mead

The ease of gaming the system had a negative impact on student effort. Despite the widespread acknowledgment of this problem, researchers heard of no national move as yet to address it, leaving teachers to seek out innovations at the margins. These included technologyinfused projects, formative assessments, and strategies for asking "questions from outside the curriculum, which increased [student] focus, " in one teacher's words. These strategies were in addition to, not instead of, official exams.

\section{Experiences within Professional Communities}

While respondents agreed that the pandemic had caused upheaval in relationships with students, they were less uniform about its impact on their relationships with peers, PD, or supervisor interactions.

Most respondents $(77 \%, \mathrm{n}=27)$ reported some shift in their interactions with colleagues, about evenly split between a "lot" and a "little," but $23 \%(n=7)$ perceived no change due to the pandemic. Cohort 3 participants were more likely to perceive significant changes. Teachers reassigned to new schools after Khbrat reported more considerable changes than those who returned to their previous schools. Qualitative data confirm that teachers who joined new professional communities during the pandemic faced major challenges in forging new relationships online. For instance, one described colleague relationships as "Zero. Absolutely never spoken to them."

Participants described transactional online communication. Some appreciated the flexibility and efficiency while others missed face-to-face interaction. While many teachers attended school occasionally, this was a logistical necessity, not an opportunity for collaboration.

Interaction is less and more formal. Once a week (...) we are there just in case a student comes and has a question. There is no communication or interaction.

(...) we don't connect at all. Like, we only have a WhatsApp group and only post if there is something really important like, "oh it's a time to post grades"

Although not typical, one teacher described how the steep learning curve needed for online teaching motivated colleagues to connect in new ways for support.

Participants perceived some positives to online PD versus face-to-face. It was convenient and promoted work/life balance. Supervisors reported increased PD attendance and anyone conducting online PD reached a broader geographic audience. There were many efforts to help teachers adjust to the basics of the new environment. Participants reported attending -- or providing -- online PD about Microsoft applications, including Teams and Forms for assessment, the Madrasati platform, or the new curriculum. While a few participants had the opportunity to train teachers on other topics, such as those of their Khbrat action plans, the priority was the pandemic response.

Technology greatly facilitated increased supervisory visits. Before, supervisors covered a wide geographical area and were lucky to visit two schools in a day; now they could observe up to six by entering any online classroom with one click. This allowed supervisors to provide support and to better understand daily instructional experiences. One teacher found the 


\section{Arab World English Journal (AWEJ) Special Issue on Covid 19 Challenges April 2021}

English K-12 Teacher Experiences is Saudi Arabia in the Pandemic Era

Daraghmeh, Mead

dynamics "better, because now even the supervisors are learning from the teachers...this has given the teachers more confidence about their ways of teaching."

Other teachers registered the changes in classroom privacy, expressing neutral, ambivalent, or negative feelings. Some experienced the increased visits by supervisors as a form of curricular control or a limit to their creativity. Attendance and performance data provided by the Madrasati platform also facilitated monitoring. Depending on the supervisor's orientation and his or her relationship with teachers, that could feel to a teacher like support or surveillance:

They can attend my class any minute without permission and without prior notice (...) there is no problem. It is normal. It is true that one gets a bit annoyed by the numerous visits...

\section{Experiences as Change Agents}

Khbrat graduates returned home with research-based action plans to implement in their schools. Topics covered many areas of EFL pedagogy including oral communication, writing, educational drama, differentiation and, formative assessment. Table 3 below shows the participant-reported implementation outcomes of these plans in January 2021.

Table 3. Implementation status for action plans

\begin{tabular}{|l|l|l|l|l|l|l|}
\hline & $\begin{array}{l}\text { Total } \\
\text { EFL }\end{array}$ & $\%$ & $\begin{array}{l}\text { Cohort 2 } \\
n\end{array}$ & $\begin{array}{l}\text { Cohort 2 } \\
\%\end{array}$ & $\begin{array}{l}\text { Cohort 3 } \\
n\end{array}$ & $\begin{array}{l}\text { Cohort 3 } \\
\%\end{array}$ \\
\hline Yes, implemented & 19 & 54.3 & 10 & 55.6 & 9 & 52.9 \\
\hline No, did not implement & 16 & 45.7 & 8 & 44.4 & 8 & 47.1 \\
\hline Totals & 35 & 100.0 & 18 & 100.0 & 17 & 100.0 \\
\hline
\end{tabular}

Over half of the participants had been able to move forward in some way with their action plans, with similar rates in each cohort. However, there was a reduction in self-reported implementation among Cohort two in January 2021 (56\%) versus November 2019 (74\%). This difference cannot fully be explained by participation because the surveys' high EFL response rates $(78 \%$ in $2021,80 \%$ in 2019) suggest substantial respondent overlap.

Nine educators (26\%) cited pandemic-related delays or challenges or said their initiatives were no longer relevant. The actual or perceived limitations of online instruction and changes in student interactions often curtailed classroom-level implementation. "My action plan is mainly focused on the classroom environment. Due to corona and online education, it's hard to implement my approach."

As demonstrated above, there was also little opportunity for colleague interactions or collaboration that might facilitate implementation. Cohort Two participants who had begun to train, coach, or collaborate with other teachers as part of their initiatives found it challenging to continue amid shifting priorities. 
Another condition affecting implementation was the practice of reassigning returning Khbrat teachers to different schools. This change compounded the disruption of the pandemic. Of the sixteen teachers who returned to the same school, $69 \%$ were able to progress with their action plans, while only $25 \%$ of the twelve reassigned to new schools reported this success.

A final challenge was a lack of systematic, follow-up support for participant initiatives. Members from both cohorts raised this concern in interviews, often without being prompted. Some commented on the perceived indifference or resistance encountered upon their return, while others invoked the idea of return on investment:

If you spend that much money and you cooperate with professional universities and educational systems... respect that. You have to plan.

\section{Discussion}

This study was conducted during a period of singularly disruptive forces in education but also of rapid social and educational change in the Kingdom of Saudi Arabia. Findings illuminate the convergence of technological, institutional, and socio-cultural factors affecting innovation in English education in the Kingdom, and suggest areas for further examination for professional support, as well as pathways to leverage virtual technology and the acquired knowledge and skills of Khbrat English teacher graduates for innovation in English instruction.

Study participants witnessed first-hand the fast, coordinated implementation of online learning through the centralized Saudi educational system, demonstrating the potential to push English language instruction forward and accelerate progress toward many Vision 2030 goals. This step towards improving English learning, however, came about with much effort and creativity beyond the core content to provide meaningful language learning experiences, as indicated by Duhoe et al. (2020), who found teachers across the spectrum of comfort with online teaching. Similarly, diverse experiences were reported even among the EFL educators of this study, all Khbrat initiative alumni.

Teachers reported more flexibility in how they taught during the pandemic compared to before, utilizing social media, videos, and websites to supplement the electronic textbook and provide more authentic English input. Yet the curricular pacing governed by the textbook continued to constrain teachers in content, time, and creativity. While the opportunity to increase language input through technology added substance to EFL instruction, following Puentedura's (2013) SAMR paradigm, this could be considered an augmentation but not yet a transformation of learning.

Despite the increase in receptive input and engagement with technology, productive practice has lagged. While the virtual environment has been less conducive to a communicative approach in EFL due to socio-cultural constraints around the use of cameras and adjustments to new expectations, midway through the 2020-21 school year, there was evidence of improvement in participation with more examples of authentic and meaningful communication activities, as defined by Rahman (2015). Overall, it is unclear whether the pandemic has been a catalyst or a deterrent in the implementation of communicative instruction in Saudi English classrooms. 


\section{Arab World English Journal (AWEJ) Special Issue on Covid 19 Challenges April 2021}

English K-12 Teacher Experiences is Saudi Arabia in the Pandemic Era

Daraghmeh, Mead

Further research is necessary on the adaptation of communicative pedagogy to online English instruction.

Participants in this study voiced concerns about online assessment, a global challenge during the pandemic. Designing authentic and reliable skill-based assessments is a complex undertaking, and online settings pose additional challenges. While assessment policies were adjusted and technology was efficiently adopted and implemented, the Saudi assessment system appears to remain aligned to the lower substitution level of Puentedura's SAMR continuum (2013), migrating traditional assessments to the online space. While some participants were able to innovate with classroom activities and formative assessment, there is not yet a broader system response to the need for a more meaningful language development assessment.

Technology such as the Madrasati platform and WhatsApp provided new pathways and efficiencies for communication between students and teachers and among educators, who recognized the benefits. Still, the lack of face-to-face contact in a "cameras off" culture presented challenges not only for language learning but also for relationship building as students and teachers sheltered in place within what Nydell (2018) described as the strictly private sphere of the family home. Participants generally felt their professional relationships were curtailed during the pandemic. Their comments reflect that virtual communication is not typically perceived as connection, which corroborates the finding from Bentahar et al. (2020) that professional collaboration was informal and relational rather than structured and scheduled. There were some examples of educators harnessing technology to communicate with each other in new ways, but they were sporadic.

On the other hand, teacher-supervisor relationships were characterized by increased accessibility. In an online environment, supervisors were one click away. Generally, interviewed supervisors expressed positive opinions about this shift; however, teachers' views varied. While the frequency of visits and means of feedback has changed, typical supervisory dynamics have not. While supervisors can better monitor teachers' performance, this may or may not promote EFL pedagogical innovation; in some cases, supervisors are still perceived as guardians of strict protocol within the hierarchical and centralized system described by Algarni and Male (2014). To move EFL instruction forward and capitalize on both greater access and acquired skills of newly trained teachers, supervision should transform from a compliance activity to a coaching and feedback model. Professional development (PD) participation witnessed a boost in the pandemic environment; physical location was no longer a barrier, and time was more available due to new teaching conditions. Again, within Puentedura's SAMR model (2013), these examples represent augmentations, where professional activities were more accessible, faster, and broader-reaching. However, as the focus was to train teachers in new technology procedures and not necessarily introduce or sustain EFL pedagogical innovations, it has not yet fully capitalized on technology to substantially transform English learning, the ultimate goal in Puentedora's framework.

Responding to pandemic conditions created an urgent priority for the Saudi educational system, which in some ways competed with EFL pedagogical innovation already underway. Interruptions and barriers are reflected, for example, in the reduced implementation rates of Khbrat action plans in January 2021 compared to November 2019 (Bentahar et al., 2020). The 


\section{Arab World English Journal (AWEJ) Special Issue on Covid 19 Challenges April 2021}

English K-12 Teacher Experiences is Saudi Arabia in the Pandemic Era

Daraghmeh, Mead

reported on-hold status of many action plans coincides with the suspension of the Khbrat program's deployment of Cohort four for the 2020-2021 year as the MoE turned its attention to the pandemic response. Although the pandemic may have exacerbated the uneven follow-up support for program participants, that issue was noted by Alsaleh (2019) and Bentahar et al. (2020).

Changing EFL education is a gradual and relational process. As Kotter (1996) states, it requires building a coalition of support with supervisors, colleagues, and students. The two groups of graduates had very different opportunities to strengthen such ties. While Cohort Two participants had a year to set their plans in motion before the pandemic, Cohort Three returned to an emergency context, and many were simultaneously challenged by reassignment to new schools. In common with educators everywhere, each participant experienced the pandemic differently. Some members of both cohorts found synergy between their EFL initiatives and online teaching. Contextualizing the implementation results within pandemic conditions may provide a reason for optimism, as over half of the EFL innovations created by Khbrat graduates are in the works.

\section{Conclusion}

In their aim to study the experiences of English teachers in Saudi Arabia during the current pandemic, the researchers identified multiple areas where further development can take place to move EFL teaching forward; a wider range of English input accompanied challenges facilitating authentic communicative output and administering valid language assessment; increased supervisor-teacher interactions counterbalanced overall fewer opportunities for collaboration among teachers; and wide-spread procedural training led to increased competence in instructional technologies but was offset by a narrow focus on EFL pedagogy. Finally, the participants had returned to Saudi Arabia to implement research-based initiatives; while over half of these are moving forward, pandemic-related delays have resulted in a decrease in progress.

This study illustrates what one participant called the "jump to the 21 st century" for Saudi education. Significant changes in teaching and learning and the use of technology occurred very rapidly throughout the country. In some ways, EFL classrooms of the 2020-2021 school year would have been unrecognizable just a few years earlier. In other ways, though, traditional approaches to curriculum, assessment, and decision-making persisted and new challenges related to online EFL contexts emerged. Pandemic conditions evolve quickly. Saudi educational experiences of the 2020-2021 school year have been quite different from those of the previous school year. As the world moves into the second year of the pandemic and students and educators continue to adjust, there are opportunities to align better with the shifts necessitated by the pandemic with best practices for EFL innovation. Based on the findings of this study, recommendations include:

1. Develop PD with a pedagogical rather than procedural focus. Best practices for teaching EFL online, including ways to promote meaningful communication and language production, should be part of future PD programs.

2. Explore and develop more authentic and valid approaches to language assessment online focusing on language production. 
Arab World English Journal (AWEJ) Special Issue on Covid 19 Challenges April 2021

English K-12 Teacher Experiences is Saudi Arabia in the Pandemic Era

Daraghmeh, Mead

3. Leverage increased virtual accessibility of supervisors to teachers and teachers to teachers more effectively by developing a collaborative culture of support and constructive feedback.

4. Provide space and time for EFL educators to build relationships and coalitions to facilitate innovation in English education.

About the Authors:

Ahlam Daraghmeh, Ph.D. has taught both English and Arabic for nearly 20 years in U.S. university and K-12 school settings and in the Middle East. She has administered ESL programs for both children and adults. For the Khbrat program at the University of Delaware, she served as an Academic Program Coordinator and faculty mentor. ORCID: https://orcid.org/0000-0001$8345-3424$

Hilary Mead, Ed.D. conducts research in the University of Delaware's College of Education and Human Development. A former English teacher with over 20 years of experience, she is passionate about building bridges between K-12 and higher education. She served as an Academic Program Coordinator, faculty mentor, and field supervisor for the Khbrat program. ORCID: https://orcid.org/0000-0003-0895-0353

Kathleen Copeland, MATESL, MAFLP has taught English learners in K-12 and university contexts for eighteen years. At the University of Delaware ELI, Ms. Copeland facilitates professional development for both U.S.-based and international ESL/EFL teachers, and served as Project Director for the Khbrat program. ORCID: https://orcid.org/0000-0003-2627-9954

\section{References}

Abu-Rmaileh, S. (2015). Students' learning styles and their effect on learning. In C. Coombe, \& R. Khan (Eds.), Best Practice in ELT: Voices from the Classroom (pp. 146-156). Dubai, UAE: TESOL Arabia Publications.

Algarni, F., \& Male, T. (2014). Leadership in Saudi Arabian public schools: Time for devolution? International Studies in Educational Administration, 42 (3), 19 - 33.

Alharbi, Y.B. (2019). A review of the current status of English as a Foreign Language (EFL) education in Saudi Arabia. Global Journal of Education and Training, 2(1), 1 - 8. Retrieved from http://www.gjetonline.com/wp-content/uploads/2018/11/vol2-Issue1Paper1.pdf

Alrabai, F. (2016). Factors underlying low achievement of Saudi EFL learners. International Journal of English Linguistics, 6 (3), 21 - 37. http://dx.doi.org/10.5539/ijel.v6n3p21

Alsaleh, B.A. (2019). K-12 education reforms in Saudi Arabia: Implications for change management and leadership education. In E.A. Samier, \& E.S. ElKaleh (Eds.), Teaching educational leadership in Muslim countries: Theoretical, historical and cultural foundations (pp. 171-186). Singapore: Springer Nature.

Al Salman, S., Alkathiri, M., \& Bawaneh, A. (2021). School off, learning on: Identification of preference and challenges among school students towards distance learning during COVID19 outbreak. International Journal of Lifelong Education, Advance online publication. DOI: $\underline{10.1080 / 02601370.2021 .1874554}$ 
Arab World English Journal (AWEJ) Special Issue on Covid 19 Challenges April 2021

English K-12 Teacher Experiences is Saudi Arabia in the Pandemic Era

Daraghmeh, Mead

Al-Shehri, S. (2020). Transforming English language education in Saudi Arabia: Why does technology matter? International Journal of Emerging Technologies in Learning, 15 (2), 108 - 123. https://doi.org/10.3991/ijet.v15i06.12655

Al-Zahrani, N. O. A., \& Rajab, H. (2017). Attitudes and perceptions of Saudi EFL teachers in implementing Kingdom of Saudi Arabia's Vision 2030. International Journal of English Language Education, 5(1), 83-99. https://doi.org/10.5296/ijele.v5i1.10733

Atmojo, A.E.P. \& Nugroho, A. (2020). EFL classes must go online! Teaching activities and challenges during the COVID-19 pandemic in Indonesia. Register Journal, 13 (1), 49 76. https://doi.org/10.18326/rgt.v13i1.49-76

Bentahar, A., Copeland, K., \& Stevens, S. (2020). Assessing Post-Teacher-Training Impact on EFL Teachers. Maryland TESOL Fall Conference, November 2020

Bond, M. (2020). Schools and emergency remote education during the COVID-19 pandemic: A living rapid systematic review. Asian Journal of Distance Education, 15(2), 191- 247. http://asianjde.org/ojs/index.php/AsianJDE/article/view/517

Bozkurt, A. et al. (2020). A global outlook to the interruption of education due to the COVID-19 pandemic: Navigating in a time of uncertainty and crisis. Asian Journal of Distance Education, 15 (1), 1 - 126. https://doi.org/10.5281/zenodo.3878572

Creswell, J.W., \& Plano Clark, V.L. (2017). Designing and conducting mixed methods research $\left(3^{\text {rd }}\right.$ Ed.). Los Angeles: SAGE Publications, Inc.

Duhoe, A. A. A., Owusu-Afriyie, R., \& Kumi, E. (2020). Examining the significance of online and distance learning management in response to crisis in education. Research Journal in Comparative Education, 1(1), 57 - 72. Retrieved from https://royalliteglobal.com/rjce/article/view/313

El-Saharty, S., Kheyfets, I., Herbst, C.H., \& Ajwad, M.I. (2020). Fostering human capital in the Gulf Cooperation Council countries. Washington, DC: World Bank. https://doi.org/10.1596/978-1-4648-1582-9_ch4

Faroque, S. (2017). Academic writing: An exploration into the factors that effects Arab students' English writing skills in private international schools in Saudi Arabia, (Unpublished Master's thesis). University of Northampton, England.

Hakim, B. (2020). Technology integrated online classrooms and the challenges faced by EFL teachers in Saudi Arabia during the COVID-19 pandemic. International Journal of Applied Linguistics and English Literature, $9 \quad$ (5), $33 \quad-\quad 39$ http://dx.doi.org/10.7575/aiac.ijalel.v.9n.5p.33

Harris, A. (2020). COVID-19: School leadership in crisis? Journal of Professional Capital and Community, 5(3/4), 321-326. DOI: 10.1108/JPCC-06-2020-0045

Harris, A. \& Jones, M. (2020) COVID 19 - school leadership in disruptive times. School $\begin{array}{lllll}\text { Leadership } \quad \text { \& } & \text { Management, } & \text { 243-247. }\end{array}$ https://doi.org/10.1080/13632434.2020.1811479

Hasan, A. (2012). Saudi Learner Issues. In W. Al-Amri, H. Noor, \& I. McGee-(Eds.), Saudi preparatory year English program: The future and beyond. Student, teacher, pedagogy and curricular issues (pp. 7-17). Madinah, Taibah University.

Kotter, J. (1996). Leading change. Boston: Harvard Business School Press.

Mabrook, A., \& Mabrook, A. (2020). Distance learning: Its impact to EFL students due to COVID-19, Onaizah Colleges, Saudi Arabia. International Journal of Contemporary Applied Researches, 7(5), 14 - 31. 
Arab World English Journal (AWEJ) Special Issue on Covid 19 Challenges April 2021

English K-12 Teacher Experiences is Saudi Arabia in the Pandemic Era

Daraghmeh, Mead

Ministry of Education (2020). The Saudi MOE: Leading efforts to combat coronavirus pandemic. Available at https://iite.unesco.org/wp-content/uploads/2020/10/The-SaudiMOE-Leading-Efforts-to-Combat-Coronavirus-Pandemic-COVID-19.pdf

Ministry of Education. (2018). Request for proposals: Building leadership for change through school immersion. Riyadh, Saudi Arabia.

Nydell, M. (2018) Understanding Arabs: A contemporary guide to Arab society (6th ed.). Boston, MA: Nicolas Brealey.

Onyema, E.M. et al. (2020). Impact of coronavirus pandemic on education. Journal of Education and Practice, 11 (13), $108 \quad$ - 121. Retrieved from https://genbase.iiep.unesco.org/workspace/applis/epidoc/fichiers/EPIDOC/38698_52821 56584_1_PB.pdf

Oxford Business Group (2020, November 5). Has COVID-19 changed GCC education forever? Available at https://oxfordbusinessgroup.com/news/has-covid-19-changed-gcc-educationforever

Puentedura, R., (2013). SAMR: Moving from enhancement to transformation. AIS ICT Management and Leadership Conference. Canberra, Australia. Available at http://www.hippasus.com/rrpweblog/archives/000095.html

Rahman, A. (2015). Voices from rural classrooms: Professional development of secondary school English teachers in Bangladesh. In C. Coombe, \& R. Khan (Eds.), Best Practice in ELT: Voices from the Classroom (pp. 95-101). Dubai, UAE: TESOL Arabia Publications.

Saudi Gazette (2020, September 26). Education Minister: 'Madrasati' platform linked to Microsoft. Available at https://saudigazette.com.sa/article/598472

Socio Cultural Research Consultants (2020). Dedoose Version 8.3.45, web application for managing, analyzing, and presenting qualitative and mixed-method research data. Available at www.dedoose.com

Tao, Y. H., Yeh, C. R., \& Sun, S. I. (2006). Improving training needs assessment processes via the Internet: system design and qualitative study. Internet Research, 16 (4), 427-49.

UNESCO: 290 Million Students Stay Home due to Coronavirus. (2020, April 3).

Available at https://rb.gy/ir1grv

Vlachopoulos, D. (2020). COVID-19: Threat or opportunity for online education? Higher Learning Research Communication, 10 (1), 16-19. DOI: 10.18870/hlrc.v10i1.1179

Zohairy, S. (2012).Professional development challenges and possible solutions. In W. Al-Amri, H. Noor, \& I. McGee, (Eds.), Saudi preparatory year English program: The future and beyond. Student, teacher, pedagogy and curricular issues. (pp. 162-183). Madinah, Taibah University. 